\title{
Analitik Hiyerarşi Süreci (AHS) Yöntemini Kullanarak Havacılık Sektörünün Kalite Süreçlerindeki İnsan Faktörü Risklerinin Değerlendirilmesi
}

\author{
Ebru Yazgan ${ }^{1 *}$ \\ 1* Eskişehir Teknik Üniversitesi, Havacılık ve Uzay Bilimleri Fakültesi, Uçak Gövde ve Motor Bakımı Bölümü, Eskişehir, Türkiye, (ORCID: 0000-0002-6545-8536), \\ eyazgan@eskisehir.edu.tr
}

(2nd International Conference on Applied Engineering and Natural Sciences ICAENS 2022, March 10-13, 2022)

(DOI: 10.31590/ejosat.1062485)

ATIF/REFERENCE: Yazgan, E. (2022). Analitik Hiyerarşi Süreci (AHS) Yöntemini Kullanarak Havacılık Sektörünün Kalite Süreçlerindeki İnsan Faktörü Risklerinin Değerlendirilmesi. Avrupa Bilim ve Teknoloji Dergisi, (34), 14-18.

Öz

Havacılık operasyonlarının sürdürülebilirliği için onaylı havacılık kuruluşlarında kalite yönetimi sisteminin kurulması gereklidir. Kalite yönetim sistemi, ilgili havacıllk işletme yönetmeliklerine uygun ve kuruluşun stratejik hedeflerini başarmak için kalite yöneticisi tarafından yürütülmektedir. Havacılık operasyonlarındaki hataların ve uçuş emniyet riskleri son derece önemli olmasından dolayı, yönetmeliklere ve insana dayalı risklerin kalite yönetimi tarafından doğru şekilde yönetilmesi hayati önem taşımaktadır. Kalite yöneticisi, havacılık operasyonlarındaki en küçük hatanın bile ölümcül olabileceği için operasyonel ortamda yasal ve mevzuata dayalı riskleri yönettiği için çok kritik bir göreve sahiptir. Bu çalışmada, havacılık ortamında kalite süreçlerindeki özellikle kalite yöneticisi için öncelikle insan risk faktörleri kategorize edilerek ve bu riskler çoklu karar verme tekniği olan, nitel faktörleri de dikkate alan Analitik Hiyerarşi Süreci (AHS) yöntemini belirlenen riskler ağırlıklandırılmıştır. Çalışma ile geliştirilen AHS modelinde kalite yöneticisi için araştırılan en önemli risk faktörleri sırasıyla zaman baskısı, yönetim desteği eksikliği ve güncel havacılık mevzuatlarının takip edilmemesi olarak belirlenmiştir. İnsan faktörleri risklerini sıralamak, üst yönetime proaktif bir yaklaşımla ilgili risklerin yönetilmesi için fayda sağlayacaktır. Bu çalışmada elde edilecek sonuçlar sayesinde kalite süreçlerindeki gelişimin, iyileşmenin ve kalite süreçlerinin kurumun stratejik amaçlarının başarılmasına katkısının büyük olması amaçlanmaktadır.

Anahtar Kelimeler: Havacılık Sektörü, Kalite Yönetim, Analitik Hiyerarşi Süreci (AHS), İnsan Faktörü.

\section{Evaluation of Human Factor Risks in Quality Processes of the Aviation Sector Using the Analytical Hierarchy Process (AHP) Method}

\begin{abstract}
For the sustainability of aviation operations, it is necessary to establish a quality management system in approved aviation organizations. The quality management system is carried out by the quality manager to comply with the relevant aviation operating regulations and to achieve the strategic objectives of the organization. Since errors and flight safety risks in aviation operations are of the utmost importance, it is vital that regulatory and human-based risks are properly managed by quality management. The quality manager has a critical role as he manages legal and regulatory risks in the operational environment as even the smallest mistake in aviation operations can be fatal. In this study, the risks determined by the Analytical Hierarchy Process (AHP) method, which is a multiple decision-making technique and also considers qualitative factors, are weighted by categorizing the human risk factors, especially for the quality manager in the quality processes in the aviation environment. In the AHP model developed by the study, the most important risk factors investigated for the quality manager were determined as time pressure, lack of management support and not following the current aviation regulations, respectively. Ranking human factors risks will benefit senior management with a proactive approach to managing the risks involved. Thanks to the results to be obtained in this study, it is aimed that the development, improvement and quality processes in quality processes will contribute to the achievement of the strategic goals of the institution.
\end{abstract}

Keywords: Aviation Sector, Quality Management, Analytical Hierarchy Process (AHP), Human Factor.

*Sorumlu Yazar: eyazgan@eskisehir.edu.tr 


\section{Giriş}

Havayolları, Havalimanları, Hava Seyrüsefer Hizmet Sağlayıcıları ve Bakım Kuruluşları vb. gibi havacılık kuruluşları, uçuş emniyeti, uçuşa elverişlilik vb. amaçlarını uygun teknik standartlara ve havacılık yönetmeliklerine uygun olarak tamamen operasyonlarla ilgili olarak maliyet etkin bir şekilde gerçekleştirmek için kalite yönetim sistemi kurarlar [1]. Havalimanları gibi kuruluşlar, kurumsal strateji amaçları için kalite hedeflerini karşılayacak, havacılık mevzuatını uygulayacak ve belgelendirme şartlarını yerine getirecek ve Türkiye'de Sivil Havacılık Genel Müdürlüğü (SHGM) gibi düzenleyici kurumlar tarafından gerekli olan Hava alanı El Kitabı kılavuzları, prosedürlerini hazırlayacaklardır. Uçağın uçuşa elverişli olması veya havalimanının emniyetli olarak çalışması havacılık faaliyetlerinin tamamen havacılık kurallarına göre doğru şeklide yönetilmesi ile sağlanmaktadır. Kalite Yöneticisi, havacılık örgütlerinde kritik bir görev yürütmekte ve mevzuat gerekliliklerini göz önünde bulundurarak havacılık kuruluşun genel kalite faaliyetlerinin koordinasyonundan sorumlu olmakta ve havacılık operasyonlarının durumu hakkında geribildirim mekanizması sağlayan denetim sürecini gerçekleştirmektedir. Ayrica denetleme sürecinin sonunda hangi konularda iyileştirmelerin yapılacağını tespit etmektedir. Kalite güvencesi, kalite gereksinimlerinin yerine getirileceğine dair güven sağlamaya odaklanan kalite yönetimi aracıdır [2]. Bu çalışmada, havacılık ortamında özellikle kalite yöneticisi için öncelikle insan risk faktörleri kategorize edilerek ve bu riskler çoklu karar verme tekniği olan, nitel faktörleri de dikkate alan Analitik Hiyerarşi Süreci (AHS) yöntemini kullanılarak ağırlıklandırılmıştır. İnsan faktörleri risklerini siralamak, üst yönetime proaktif bir yaklaşımla ilgili risklerin yönetilmesi için fayda sağlayacaktır. Farklı kuruluşlar için AHS modelinin geliştirilmesinin benzer uygulamalar için farkındalığın artmasına yol açacağı da son derece önemlidir. Projede geliştirilen AHS modeliyle hem literatüre ve hem de insan faktörleri alanına katkıda bulunacağ hedeflenmiştir.

\section{Analitik Hiyerarşi Süreci}

Analitik Hiyerarşi Süreci (AHS) Saaty tarafından geliştirilen yaygın olarak kullanılan çok kriterli karar verme tekniklerinden biridir. AHS'de karar vericinin amacı doğrultusunda kriterler ve ona ait alt kriterler ile alternatiflerden oluşan hiyerarşik bir model kullanılır. AHS yöntemi karar vermede uzman görüşlerini dikkate alan, nitel ve nicel değişkenleri bir arada değerlendiren matematiksel bir yöntemdir $[3,4,5,6]$. Literatürde AHS yaklaşımı iş değerlendirme sürecin [3] havayolları pilot adaylarının seçimin [7], yer seçiminde [8], makine seçiminde [9], banka performans değerlendirme [10], enerji [11], tedarikçi seçimi [12] ve kalite kontrol [13] gibi çok farklı alanlarda yaygın olarak uygulandığı görülmüştür.

AHS yönteminde ikili karşılaştırmalar temel yapı taşlarıdır. Kriterler arası ikili karşılaştırmalar yapılırken, Tablo 1'de görülen ve Saaty tarafından önerilen 1'den 9'a kadar değerler içeren temel karşılaştırma skalası kullanılmaktadır [3, 14].
Tablo 1. Önem skala değerleri ve tanımlart

\begin{tabular}{|c|c|c|}
\hline Değer & Tanım & Açıklama \\
\hline 1 & Eşit önemli & $\begin{array}{l}\text { İki seçenekte eşit derecede } \\
\text { öneme sahip }\end{array}$ \\
\hline 3 & $\begin{array}{l}\text { Orta derecede } \\
\text { önemli }\end{array}$ & $\begin{array}{l}\text { Tecrübe ve yargı bir kriteri } \\
\text { diğerine karşı biraz üstün } \\
\text { kılmakta }\end{array}$ \\
\hline 5 & $\begin{array}{l}\text { Kuvvetli } \\
\text { derecede } \\
\text { önemli }\end{array}$ & $\begin{array}{l}\text { Tecrübe ve yargı bir kriteri } \\
\text { diğerine karşı oldukça üstün }\end{array}$ \\
\hline 7 & $\begin{array}{l}\text { Çok kuvvetli } \\
\text { derecede } \\
\text { önemli }\end{array}$ & $\begin{array}{l}\text { Bir kriter diğerine göre } \\
\text { üstün sayılmıştır }\end{array}$ \\
\hline 9 & Kesin önemli & $\begin{array}{l}\text { Bir kriterin diğerinden üstün } \\
\text { olduğunu gösteren kanıt çok } \\
\text { büyük güvenilirliğe sahiptir }\end{array}$ \\
\hline $2,4,6,8$ & Ara değerler & $\begin{array}{lc}\text { Uzlaşma } & \text { gerektiğinde } \\
\text { kullanılmak } & \text { üzere iki } \\
\text { ardışık yargı } & \text { arasındaki } \\
\text { değerler } & \end{array}$ \\
\hline
\end{tabular}

AHS'de öncelikle problemin tanımlanması yapılır ve amaç belirlenir. Daha sonra kriterler ve varsa alt kriterler saptanır. En alt seviyede ise bu kriterleri sağlayan alternatifler yer almaktadır. $\mathrm{Bu}$ aşamada karar sürecini etkileyen tüm kriterlerin belirlenebilmesi için anket çalışmasına veya bu konuda uzman kişilerin görüşlerine başvurulmaktadır. Daha sonra ikili karşılaştırma matrisleri oluşturularak karar vericiden kriterleri ikili karşılaştırmaları yapması istenmektedir. $\mathrm{Bu}$ karşılaştırmalarda bulunan değer 0,10'un altında çıkmışsa oluşturulan karşılaştırma matrisinin tutarlı olduğu sonucuna varılır. Aksi durumda karşılaştırma matrisi tutarsızdır ve karar vericiden kararını gözden geçirerek düzeltmesi istenmektedir. Daha sonra ikili karşılaştırma matrislerinden göreli ağırlıklar (özvektör değerleri) hesaplanmaktadır $[3,14]$.

\section{Havacılık Sektörünün Kalite Süreçlerindekı İnsan Faktörü Risklerinin Ağırlıklandırılmasında AHS Yönteminin Uygulaması}

Çalışmada Analitik Hiyerarşi Süreci (AHS) yaklaşımı kullanılarak kalite süreçlerindeki özellikle kalite müdüründen kaynaklı insan faktörü riskleri öncelikle belirlenerek ve daha sonrada geliştirilen AHS modelinde havacılık sektöründeki uzmanların düşünceleri alınarak belirlenen riskler sıralanmıştır. Bu çalışmadaki havacılık ortamında özellikle kalite yöneticisi için öncelikle insan risk faktörleri; güncel olmayan havacılık mevzuatlarının takip edilmemesi, uzmanlık (teknik bilgi), tecrübe, sosyal uyumsuzluk, saldırganlık, disiplinsizlik, yorgunluk gibi "kişiye ilişkin faktörler" ve zaman baskısı, yönetim desteği eksikliği, kalite yönetimi/denetçi eğitimi vb. gibi uygun olmayan personel eğitimi almak, kurumsal değişim / yeniden yapılanma ve motivasyon (ödül, ceza vb.) gibi “organizasyonla ilgili faktörler" şeklinde kategorize edilerek 
AHS modeli geliştirilmiştir. "Super Decision" yazılımı yardımıyla elde edilen AHS modelinin hiyerarşik program görüntüsü Şekil 1'de verilmiştir.

Yapılan ikili karşılaştırmalar sonucu AHS modelinde yer alan havacılık sektöründe kalite müdüründen kaynaklı insan faktörü kriterlerinin normalize edilmiş ve limiti alınmış ağırlıkları Tablo 2' de verilmiştir.

\section{Tartışma ve Sonuçlar}

AHS modeli yardımıyla havacılıkta kalite yöneticisi için araştırılan en önemli risk kriterleri Tablo 2'den de görüldüğü üzere sırasıyla zaman baskısı, yönetim desteği eksikliği ve güncel havacılık mevzuatlarının takip edilmemesidir. Zaman baskısı havacilıktaki tüm birimler için majör bir faktör olup zaman baskısı gibi bir riski yönetmek için kalite yöneticisi yaptığı işleri önceliklendirmesi, ekipteki arkadaşlarına işleri paylaştırması, işleri bitirme için bir son tarih belirleme vb. göz önünde bulundurabilir. Kalite Yöneticisi havacılık işletmelerinde doğrudan genel müdüre bağlı olarak ve diğer birimlerden bağımsız olarak çalışmaktadır. Kurum içindeki denetlemelerde tespit edeceği havacılık mevzuatlarına uygun olmayan bulguların birim amirleri tarafindan düzeltilmesinde yönetimin desteği çok kritiktir. $\mathrm{Bu}$ nedenle çalışmada yönetim desteğine ilişkin risk faktörü uçuş emniyeti ve havacılık operasyonlarının en etkin ve verimli şekilde yönetilmesinde dikkate alınması gereken en önemli faktörlerden biri olduğu görülmüştür. En önemli 3. faktör güncel havacılık mevzuatlarının takip edilmemesi olarak belirlenmiştir. Kalite yöneticisi tarafindan operasyonlarının havacılık mevzuatlarına uygunluğunun belirlenmesi için yapılan denetlemelerde gerek ulusal gerek uluslararası mevzuatlarının güncelliğini düzenli olarak takip edilmesi çok önemlidir aksi halde işletmenin sahip olduğu yetkiler riske girecektir. Böylece bu çalışmada geliştirilen AHP modeli sayesinde elde edilen sıralama da öncelikli riskler tespit edilerek üst yönetime riskleri yönetebilmek için proaktif bir yaklaşımla gerekli önlemleri alması amaçlanmıştır. $\mathrm{Bu}$ çalışmanın sonuçları, havacılık endüstrisinde çalışan diğer çalışanlara örnek teşkil edebilir ve yöneticiler için birçok benzer riske karar vermede kullanılabilir. $\mathrm{Bu}$ çalışmada elde edilecek sonuçlar sayesinde kalite süreçlerindeki gelişimin, iyileşmenin ve kalite süreçlerinin kurumun stratejik amaçlarının başarılmasına katkısının büyük olması amaçlanmıştır.

AHS modelinin sonuçları ile risk değerlendirmelerinin risk faktörlerini doğru tespit ederek ve siralayarak gerçekleştirildiğinde ilgili havacılık kuruluşlarına rehberlik edeceği amaçlanmaktadır. Bu çalışma, kuruluşlarda risk azaltma planlarını yapacak üst yönetim düzeyini dikkate alarak yürütülecektir. Kalite biriminde insan faktörü riskinin, özellikle de kalite yöneticisi ile ilgili olarak havalimanının veya diğer havacılık operasyonlarının kalite sürdürülebilirliği için yönetilmesi esastır. Bununla birlikte Projede geliştirilen AHS modeliyle hem literatüre ve hem de insan faktörleri alanına katkıda bulunacağı hedeflenmiştir. Bu çalışmanın sonuçları, havacılık endüstrisinde çalışan diğer çalışanlara örnek teşkil edebilir ve yöneticiler için birçok benzer riske karar vermede kullanılabilir.

\section{Teşekkür}

Bu çalışma, Eskişehir Teknik Üniversitesi Bilimsel Araştırma Projeleri Komisyonu (Proje Numarası: 19ADP116) tarafindan desteklenmiştir. 


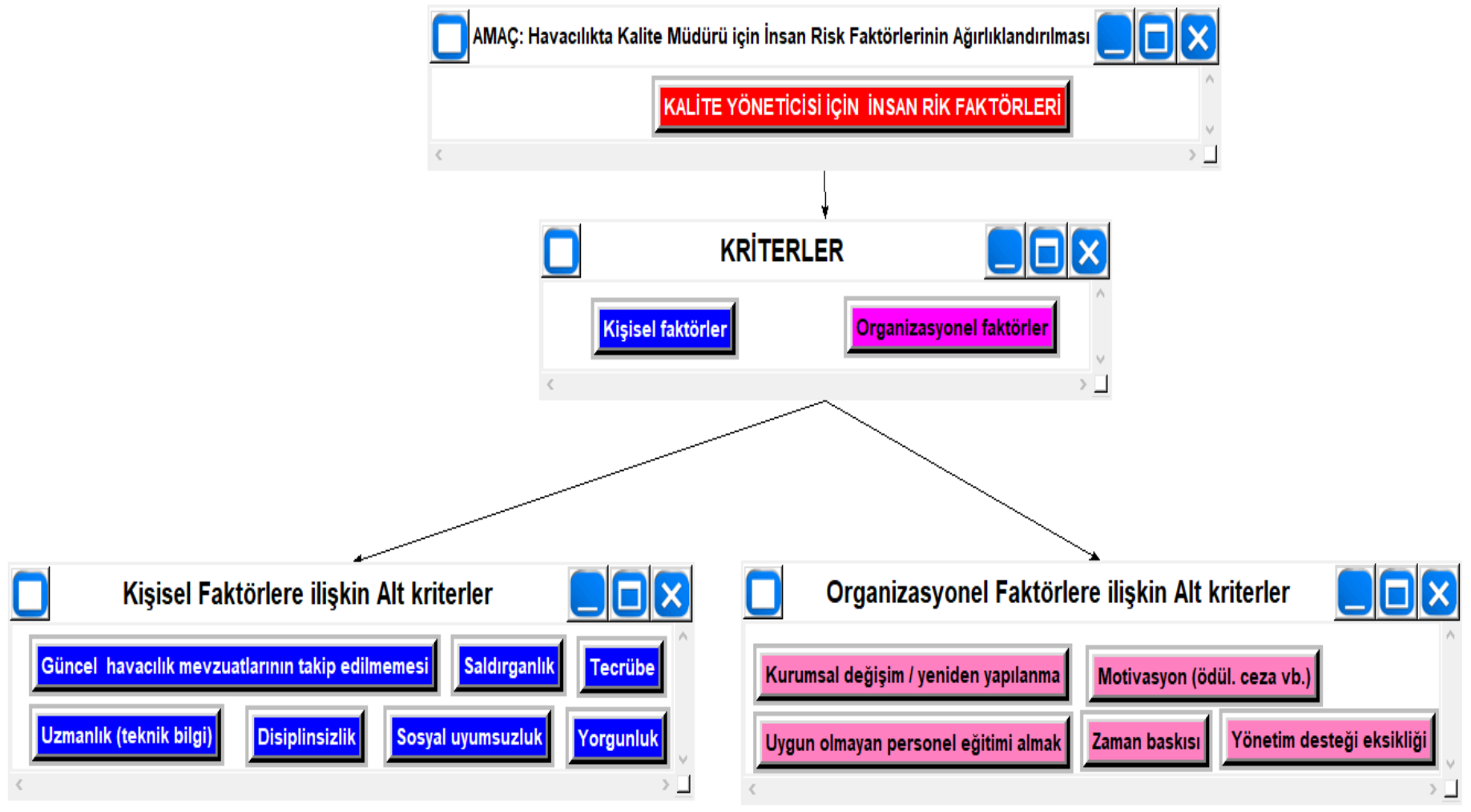

Şekil 1. AHS Modelinin Hiyerarşik Görüntüsü

Tablo 2. Havacılık Sektöründe Kalite Müdüründen Kaynaklı İnsan Faktörü Kriterlerinin Ağırllkları

\begin{tabular}{|lcc|}
\hline Kriter Adı & $\begin{array}{c}\text { Kümeye göre } \\
\text { Normalize edilmişağırlıklar }\end{array}$ & $\begin{array}{c}\text { Limiti alınmış } \\
\text { ağırlıklar }\end{array}$ \\
\hline Kişisel faktörler & 0.50000 & 0.250000 \\
\hline Organizasyonel faktörler & 0.50000 & 0.250000 \\
\hline KALİTE YÖNETICİSİ İÇIN İNSAN RİK FAKTÖRLERİ & 0.00000 & 0.000000 \\
\hline Yorgunluk & 0.21992 & 0.054981 \\
\hline Güncel havacılık mevzuatlarının takip edilmemesi & 0.22829 & 0.057073 \\
\hline Disiplinsizlik & 0.18698 & 0.046744 \\
\hline Saldırganlık & 0.11974 & 0.029935 \\
\hline Sosyal uyumsuzluk & 0.07959 & 0.019897 \\
\hline Tecrübe & 0.09846 & 0.024615 \\
\hline Uzmanlık (teknik bilgi) & 0.06702 & 0.016755 \\
\hline Kurumsal değişim / yeniden yapılanma & 0.09622 & 0.024055 \\
\hline Yönetim desteği eksikliği & 0.24535 & 0.061337 \\
\hline Motivasyon (ödül. ceza vb.) & 0.15797 & 0.039492 \\
\hline Uygun olmayan personel eğitimi almak & 0.09766 & 0.024415 \\
\hline Zaman baskısı & 0.40280 & 0.100700 \\
\hline
\end{tabular}




\section{Kaynakça}

[1] Joint Aviation Authorities (JAA), (2013). Quality management - principles \& practice in an aviation environment..

[2] ISO 9000:2005, Clause 3.2.11.

[3] Dağdeviren, M., Akay, D. ve Kurt, M. (2004). İş değerleme sürecinde analitik hiyerarşi prosesi ve uygulaması. Gazi Üniversitesi Mimarlık Mühendislik Fakültesi Dergisi, 19 (2), 131-138

[4] Saaty, T.(1980). The Analytic Hierarchy Process, McGrawHill International Book Company, USA.

[5] Topçu, Y.İ. (2007). Karar verme ve destek sistemleri. 15 Temmuz 2009, http://www.isl.itu.edu.tr/ya/KDS2.ppt.

[6] Çanlı, H. ve Kandakoğlu, A. (2007). Hava gücü mukayesesi için bulanık AHP modeli. Havacılık ve Uzay Teknolojileri Dergisi, 3 (1), 71-82.

[7] Oktal, H. ve Onrat, A. (2020). Analytic Hierarchy ProcessBased Selection Method for Airline Pilot Candidates, The International Journal of Aerospace Psychology, 30:34, 268-281, DOI: $10.1080 / 24721840.2020 .1816469$

[8] Badri, M. A. (1999). Combining the analytic hierarchy process and goal programming for global facility locationallocation problem, International Journal of Production Economics, 62(3), 237- 248, 1999.

[9] Myint, S. ve Tabucanon, M.T., (1994). A multiplecriteria approach to machine selection for flexible manufacturing systems, International Journal of Production Economics, 33(1-3), 121-131.

[10] Albayrak, Y. E. ve Erkut, H. (2005), Banka Performans Değerlendirmede Analitik Hiyerarşi Süreç Yaklaşımı, İTÜ Dergisi, Cilt :4, Say1:6, ss 47-58.

[11] Ramanathan, R. ve Ganesh, L. S. (1995). Energy alternatives for lighting in households: an evaluation using an integrated goal programming AHP model, Energy, 20(1), 63-72.

[12] Özyörük, Y. ve Özcan, E. C. (2008). Analitik Hiyerarşi Sürecinin Tedarikçi Seçiminde Uygulanması: Otomotiv Sektöründen Bir Örnek. Süleyman Demirel Üniversitesi İktisadi ve İdari Bilimler Fakültesi Dergisi, 13 (1, 133-144 . https://dergipark.org.tr/en/pub/sduiibfd/issue/20834/22321 $\underline{5}$

[13] Badri, M. A. (2001). A combined AHP-GP model for quality control systems, International Journal of Production Economics, 72(1), 27-40.

[14] Ömürbek, N., Üstündağ, S. \& Helvacioğlu, Ö. C. (2013). Kuruluş Yeri Seçiminde Analitik Hiyerarşi Süreci (AHP) Kullanımı: Isparta Bölgesinde Bir Uygulama. Yönetim Bilimleri Dergisi, 11 (21), 101-116. https://dergipark.org.tr/en/pub/comuybd/issue/4102/54042 